\title{
Development of an explanatory model of sexual intimacy following treatment for localised prostate cancer: A systematic review and meta-synthesis of qualitative evidence
}

DOI:

10.1016/j.socscimed.2016.07.001

\section{Document Version}

Accepted author manuscript

Link to publication record in Manchester Research Explorer

\section{Citation for published version (APA):}

Tucker, S., Speer, S., \& Peters, S. (2016). Development of an explanatory model of sexual intimacy following treatment for localised prostate cancer: A systematic review and meta-synthesis of qualitative evidence. Social Science and Medicine, 163, 80-88. https://doi.org/10.1016/j.socscimed.2016.07.001

\section{Published in:}

Social Science and Medicine

\section{Citing this paper}

Please note that where the full-text provided on Manchester Research Explorer is the Author Accepted Manuscript or Proof version this may differ from the final Published version. If citing, it is advised that you check and use the publisher's definitive version.

\section{General rights}

Copyright and moral rights for the publications made accessible in the Research Explorer are retained by the authors and/or other copyright owners and it is a condition of accessing publications that users recognise and abide by the legal requirements associated with these rights.

\section{Takedown policy}

If you believe that this document breaches copyright please refer to the University of Manchester's Takedown Procedures [http://man.ac.uk/04Y6Bo] or contact uml.scholarlycommunications@manchester.ac.uk providing relevant details, so we can investigate your claim.

\section{OPEN ACCESS}


This is the authors' final, pre-publication version of the paper to be published in the journal, Social Science \& Medicine. Some small changes may have occurred after this version was sent to publication. The final published version should be consulted before quoting or discussing in detail.

\title{
Development of an explanatory model of sexual intimacy following treatment for localised prostate cancer: A systematic review and meta- synthesis of qualitative evidence
}

\author{
Samantha R Tucker ${ }^{\mathrm{a}}$, Susan A Speer ${ }^{\mathrm{a}}$, Sarah Peters ${ }^{\mathrm{a}}$
}

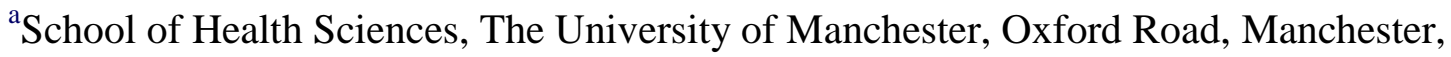
M13 9PL, UK

Samantha Tucker - samantha.tucker@postgrad.manchester.ac.uk

Susan Speer - susan.speer@manchester.ac.uk

* Sarah Peters - sarah.peters@manchester.ac.uk

* Corresponding author:

Dr Sarah Peters

School of Health Sciences

Coupland Building 1

The University of Manchester

Oxford Road

Manchester M13 9PL

UK

Tel.: +4401612752558

E-mail: sarah.peters@manchester.ac.uk

\section{Author Contribution}

The study was undertaken by Samantha R Tucker as part of the degree of Doctor of Clinical Psychology (ClinPsyD) supervised by Sarah Peters and Susan A Speer, who conceived of the idea and, with Samantha R Tucker, designed the study and developed the search strategy. Samantha R Tucker conducted the search, screened the papers and developed the analysis. Sarah Peters and Susan A Speer contributed to the final development of the LMAC model. Samantha R Tucker drafted the paper, which was finalised by Sarah Peters and Susan A Speer. Sarah Peters is the guarantor for the study and paper. 


\section{Development of an explanatory model of sexual intimacy following treatment for localised prostate cancer: A systematic review and meta-synthesis of qualitative evidence}

\section{ABSTRACT}

Rationale: Prostate cancer is a leading cause of cancer in men, affecting one in eight. An ageing population coupled with increased testing indicates that the incidence of earlystage prostate cancer is rising rapidly. Treatments are effective, but all can result in chronic sexual side effects and impact on the psychological, emotional and relational components of sexual functioning. Whilst the physical consequences of treatment are well documented, we lack a comprehensive picture of the effects of localised prostate cancer treatment on men's experience of sexual intimacy and how this may affect survivorship and recovery.

Objective: This study synthesises the qualitative literature related to men's experience of sexual intimacy in the context of localised prostate cancer.

Methods: A systematic search strategy identified 12 studies, which were assessed using a modified version of the Critical Appraisal Skills Programme. Using Noblit and Hare's (1988) approach, a meta-synthesis was conducted.

Results: Findings are organised within four inter-related themes that form the basis of a new conceptual explanatory model: (i) Loss and grief: Destroyed intimacy; (ii) Going through the motions: Artificial intimacy; (iii) Fear of failure: Avoiding intimacy and (iv) Breaking barriers: Constructing an alternative intimacy. 
Conclusion: The LMAC (Loss, Motions, Avoidance and Construction) model provides a new way of conceptualising sexual recovery following prostate cancer treatment and opportunities for health care professionals to support men and their partners.

KEYWORDS: Meta-synthesis; systematic review; prostate cancer; side effects; Sexual intimacy

\section{RESEARCH HIGHLIGHTS}

- Research on sexual intimacy after prostate cancer is limited in scope.

- Explanatory model shows sexual intimacy in following localised prostate cancer.

- Sexual intimacy can regress and progress in the wake of treatment.

- Clinicians should enhance access to support tailored to men's needs. 


\section{INTRODUCTION}

The global burden of prostate cancer (PC) is extreme; an estimated 1.1 million patients were diagnosed worldwide in 2012 (Ferlay et al., 2015) and approximately one in eight men will have PC at some point in their lives (Prostate Cancer UK, 2013). The incidence of the disease has increased in recent years because of an ageing population (PC is more common in men over 50 years) alongside increased availability of the prostate-specific antigen-screening test (Quinn and Babb, 2002). Earlier diagnosis means most (81\%) patients are clinically localised (confined to the prostate gland) and chances of survival are very high (Siegel, Naishadham and Jemal, 2013): The 5-year relative survival for localised prostate cancer (LPC) ranges between 90\% and100\% (Tracey et al., 2007; Ries et al., 2008; Cancer Research UK, 2012). Indeed most newly diagnosed men will die from a cause other than PC (Epstein et al., 2012). Consequently, a growing population of men are living for many years with the physical and emotional reverberations of LPC treatment.

The most common active treatment options for LPC are radical prostatectomy and radiation therapy, including brachytherapy (Heidenreich et al., 2013). Both options have chronic sexual side effects, which include erectile dysfunction (ED), changes to penis shape and diminished libido and ability to ejaculate (Chung and Brock, 2013; Heidenreich et al., 2013). These effects extend beyond the mechanics of sexual function to the experience of sexual intimacy (the psychological, emotional and relational components of sexual functioning) (Hawkins et al., 2009; Perz, Ussher and Gilbert, 2013). Sexual intimacy is an important quality-of-life consideration for illness survivors (Steinke, 2005), and has been shown to facilitate adjustment and recovery from cancer and its treatment (e.g. Schultz and van de Wiel, 2003; Wilmoth, 2001). Amongst female gynaecological cancer survivors, psychological well-being and quality of intimate 
attachments have been identified as greater predictors of post-treatment sexual satisfaction and quality of life than physical recovery (Anderson, Woods and Copeland, 1997). In light of the profound changes to sexual functioning associated with PC treatment, sexual intimacy is central when considering post-treatment outcome (Beck, Robinson and Carlson, 2009) and has been continuously flagged as problematic in patient questionnaire studies (e.g. Badr and Carmack Taylor, 2009). Consequently, it is argued that patients' thoughts and feelings about sexual intimacy following cancer treatment should be assessed, and sexual intimacy encouraged in those who are interested in maintaining it (Hordern, 2008).

Only relatively recently, have qualitative methods been used to investigate the importance of sexual intimacy specific to PC survivors. An attempt to aggregate the findings in this area (Beck et al., 2009) took a conceptual rather than an empirical approach and did not include any systematic evaluation or synthesis of studies. Nonetheless, they identified that several psychosexual effects of PC treatment (including difficulties with body image and masculinity, reduced self-esteem and impaired quality of partner/marital relationships) negatively affected the experience of sexual intimacy (Beck et al., 2009). The authors declared a need for 'research that focuses exclusively on the issue of sexual intimacy' and more specifically 'research focusing on the successful strategies used by couples to maintain sexual intimacy' (Beck et al., 2009, p142). Whilst this review prompted more qualitative investigation to understand men's psychosexual experience, no further attempt towards systematic synthesis has been made. In order to address this gap, we aim to use a meta-synthesis approach to expand the interpretive possibilities of the individual studies in this area and construct a larger interpretive narrative (Sandelowski, Docherty and Emden, 1997) to answer the question: What happens to sexual intimacy following treatment for LPC? 


\section{METHODS}

This study followed Noblit and Hare's approach (1988), which seeks to build explanatory theory by synthesising qualitative evidence. Individual studies are brought together to form a 'whole' that is higher than the sum of its parts (Strike and Posner, 1983).

\section{Search strategy and data sources}

A search strategy was developed as recommended by Petticrew and Roberts (2006) that included keywords (and their truncated variants) that described the population of interest (e.g. 'LPC' and 'treatment'), the phenomena under investigation ('sexual intimacy', 'sexuality') and the type of studies of interest ('qualitative', 'interviews'). In order to develop a tailored search strategy that balanced sensitivity and specificity, the search strategy outlined by the Hawaii Medical Library for the CINAHL database (Petticrew and Roberts, 2006), with additions by Shaw et al., (2004), was consulted to develop evidence-based filters for qualitative research. The search strategy was applied to four electronic databases (PsycINFO, Embase, MEDLINE, Web of Knowledge) in June 2014 and updated in March 2015 (an example is given in Appendix 1).

\section{Inclusion and Exclusion Criteria}

Studies were included if they: (a) involved empirical qualitative research which (b) illuminated men's experiences of sexual intimacy (i.e. the emotional and relational components of sexual functioning), (c) as experienced by heterosexual men who are undergoing or have undergone active (pharmacological, radiological or surgical) treatment for LPC. No restrictions were imposed on the date of publication or language, 
or on the length of time between treatment and data collection. Studies of untreated PC or where the disease was monitored via expectant management (watchful waiting) or active surveillance were excluded. Studies of men with advanced, metastatic PC were excluded as prognosis and management differs significantly from those with LPC (Navon and Morag, 2003). Grey literature (i.e. unpublished or non-peer-reviewed reports including conference proceedings) was excluded as the studies may be incomplete and methodological quality is difficult to assess (Sacks et al., 1996).

\section{Results of Search Strategy}

The search yielded 2503 publications following the exclusion of duplicates $(n=1304)$. Titles and abstracts were screened against the inclusion and exclusion criteria. A total of 2407 records were excluded at this stage on the grounds of quantitative design or because they were not related to psychosexual experience. The remaining, potentially relevant, studies $(n=96)$ were read in full to assess eligibility by the lead author. A second author (Sarah Peters) independently read all those initially identified as eligible and any that were considered as potentially eligible, blind to their status $(n=16)$. Disagreements about inclusion were resolved in an iterative process via discussion and refinement of the inclusion/exclusion criteria until 100\% agreement was achieved.

Twelve qualitative articles met the inclusion criteria. Reference lists of the included articles and the one relevant review article were hand-searched. This failed to reveal additional relevant articles. Four of the studies included the views of female partners; however, the synthesis focused upon findings relating to men's perspectives. Despite differences in specific aims across the 12 studies, it is indicative of the importance of 
men's experience of sexual intimacy that views on the subject arose even in studies which did not explicitly aim to investigate sexual intimacy. The identification and selection of the synthesised articles is presented in a PRISMA (Preferred Reporting Items for Systematic Reviews and Meta-Analyses) flow chart (Moher et al., 2009) (see Figure $1)$. 


\section{Critical appraisal}

Papers were critically appraised for rigour, credibility and relevance using an adapted Critical Appraisal Skills Programme (CASP) checklist (CASP, 2010) and categorisation devised by Dixon-Woods et al. (2007), which is used widely in meta-syntheses (e.g. Bayliss et al., 2014; Jackson and Roberts, 2015). Studies were individually rated using a three-point system (e.g. 0 = serious methodological issues; 1 = minor methodological issues and $2=$ Robust) along three dimensions: (i) relevance of the paper in relation to the present research question; (ii) value of the paper in terms of answering the research question and (iii) methodological quality. Scores were totalled and classed as 'Key', 'Satisfactory' or 'Fatally Flawed'. Those that did not sufficiently address men's experience of sexual intimacy in the context of LPC treatment are categorised as 'Irrelevant'. We intended to exclude 'Fatally Flawed' or 'Irrelevant' papers; however, none was classed as such. Hence, all 12 papers identified by the search strategy were included in the synthesis. Evidence suggests negligible difference between 'key' and 'satisfactory' papers in terms of contribution to analysis (Malpass et al., 2009); hence, studies were weighted equally in the synthesis. An independent researcher, blind to the scores, rated each paper using the CASP. A 95\% agreement between the rates indicated a high level of inter-rater reliability.

\section{Synthesis of studies}

Data extraction and synthesis progressed as outlined by Noblit and Hare (1988) and as adapted for health research (e.g. Britten et al., 2002). The concept of first-, second- and third-order constructs informed data extraction (Schutz, 1962). First-order constructs are participants' views and interpretations of their experience expressed as direct participant 
quotations. Second-order constructs are the authors' views and interpretations of the participants' quotes, extracted from the Results and Discussion sections of papers. Thirdorder constructs are the synthesised constructs that emerged from the analysis of firstand second-order constructs.

Papers were read and re-read. First- and second-order constructs were extracted and managed in tables to determine how studies were related. Reviewing the tables allowed the findings and interpretations of individual studies to be juxtaposed, compared and reciprocally translated to identity themes in the data. The researchers recorded which papers contributed to each theme, in terms of relevant data or contradictory results. These translations were then synthesised to derive third-order constructs that both reflected and extended beyond the original findings of the 12 studies. The analysis was led by the first author, but all authors regularly met to discuss, refine and agree upon emergent themes.

\section{RESULTS}

\section{Study characteristics}

Across the studies, data were provided by 182 heterosexual males (aged $45-84$ years). Time between treatment completion and interview ranged from 3 months to 25 years. All papers were methodologically sufficient. Minor methodological issues were identified in six studies and primarily pertained to whether the researchers had critically examined their own role, potential bias and influence during formulation of the research questions and data collection. Key papers considered these points, whereas satisfactory papers generally did not offer such reflections. Furthermore, key papers tended to be more 
explicit, and offer more detailed description about ethical issues and the data analysis. Table 1 provides an overview.

[Table 1 about here]

\section{Summary of synthesis}

Four inter-related themes formed the basis of a conceptual explanatory model illustrating the key experiences of sexual intimacy in the context of LPC treatment and the ways sexual intimacy can change, sometimes progressing and sometimes retrogressing in the wake of treatment (see Figure 2). The themes, or forms of sexual intimacy, are (1) Loss and grief: Destroyed intimacy, (2) Going through the motions: Artificial intimacy, (3) Fear of failure: Avoiding intimacy and (4) Breaking barriers: Constructing alternative intimacy. Together these form the proposed LMAC (Loss, Motions, Avoidance and Construction) model of sexual intimacy following LPC treatment.

\section{Loss and grief: Destroyed intimacy}

Across the synthesised studies, LPC treatment was associated with significant urogenital side effects such as ED. This prompted a sense of loss, particularly for those who 'placed a relatively high value on sex for physical pleasure and a relatively low value on sex for relational intimacy' [Author quote, [Beck et al., 2013, p.1641]. However, the real detriment to sexual intimacy related less directly to the loss of penetrative intercourse, and more to the far-reaching psychological and relational changes associated with ED [e.g. Beck et al., 2013; Bokhour et al., 2001]. As noted by one author, 'many emotive 
changes and challenges accompanied the loss of potency' resulting in a radically disordered intimate life [Author quote, [Oliffe, 2005, p.2254]. Men reported significant losses in the psychosexual realms of eroticism, fantasy life, sexual desire and libido [Bokhour et al., 2001; Rivers et al., 2011], which significantly affected their motivation for intimate relations:

'You don't have any feelings for sex [sexual desire]. That really upset my whole life'. [Participant quote, [Rivers et al., 2011, p.109]

Men's manifold loss led many to view their post-treatment sexual self as a 'failure' [Beck et al. 2013; de Moraes Lopes et al., 2012]. They felt diminished as a man and as a lover because of treatment:

'Ifeel, well, [like] a man who is mutilated. I'm only a half human because the desire and the ability for sexual activity is lost'. [Participant quote, [Hedestig et al., 2005, p.681]

Loss was often equated with anxiety, sadness, frustration and difficulties relating to their partner:

'The physical distance has an effect on the depth of the relations between us'.

[Participant quote, [Eilat-Tsanani et al., 2013, p.155] 
Ultimately, ED was far more than a physical symptom. For some, the destruction of sexuality as they knew it led them to stop engaging in sexual intimacy all together leading to a void, which was described as akin to grief:

'not having sex-we've discussed it that there's nothing we can do, so there's no sex life in our place...there's no sexual intimacy'. [Participant quote, [Hanly et al., 2014]

'Losing their erectile function, however, radically changed their sex life, which gave them a sense of grief'. [Author quote, Hedestig et al., 2005, p.681]

\section{Going through the motions: Artificial intimacy}

Following the loss left by treatment, pro-erectile aids such as mechanical assistive devices and oral or injected medications were the first-line intervention prescribed. This often represented the next form of sexual intimacy encountered. Initially men saw penile rehabilitation as a way of managing the sexual side effects of treatment and recoup the damage to their intimate lives. However, the rewards of assistive aids rarely matched the physical and emotional effort of their execution:

'they get you believing that if you do these things it is going to work, but it doesn' $t$ ' [Participant quote, [Letts et al., 2010, p.501].

Even when the aids achieved operational proficiency, for most men the extent to which mechanically assisted erections recaptured sexual intimacy in their relationship was limited. 
'I used the pump for the first three months as part of that process of rehab, and it's such a pain to go through all that assembly and disassembly, and it's just too much monkey motion for me’. [Participant quote, [Wittmann et al., 2014, p.2511]

The aids rendered sexual relations offputtingly artificial to the extent that 'the time required and the awkward and cumbersome use of assistive aids often eclipsed the sexual appetite' [Author quote, [Beck et al. 2013, p.1645]. Mechanically assisted erections lacked the spontaneity, romance and playfulness men fondly remembered from their pretreatment sex lives; the elements that elevated sex to sexual intimacy. Some men reported restoration (or part-restoration) of sexual functioning contributed to constructing an alternative sexual intimacy and allowed them to feel pride and restate their masculine identity.

'Since having the needles it's given me a lot more confidence...it's a lovely feeling, you feel very proud of yourself. You put the needle in and everything's working again. Being a selfish male and my ego... ' [Participant quote, [Hanly et al., 2014, p.5].

However, most found this alternative form of encounter unsatisfactory.

'So, yes, there is a sex life but it's a rather unnatural one' [Participant quote, [Bokhour et al., 2001, p.651]. 
This often resulted in a reluctance to persevere with assistive aids and many abandoned them altogether. Ultimately, artificially induced erectile function was not synonymous with the recovery of sexual intimacy.

\section{Fear of failure: Avoiding intimacy}

Men's sense of disappointment and failure often led to maladaptive coping such as distancing, withdrawal and avoidance of intimacy in response to feelings of embarrassment, shame, helplessness, anxiety and depression [de Moraes Lopes et al., 2012; Hanly et al., 2014] and guilt 'because of the inability to function as a male' [Author quote, Eliat-Tsanani et al., 2013, p.155]. Men became apprehensive about partaking in sexual activity for fear of disappointing their partner, or as one man put it 'starting a fire you can't put out' [Participant quote, Bokhour et al., 2001]. These men doubted about their ability to deliver sexual satisfaction, which discouraged them from making intimate overtures:

'It's the part of the fear of trying you know, what if it doesn't work...you worry about, are you satisfying your partner?' [Participant quote, Wittmann et al., 2014, p.2512]

Such performance anxiety often resulted 'in a negative feedback loop in which disappointing sexual encounters reduced the frequency and intensity of future sexual desire' [Author quote, Beck et al., 2013, p.1645]. The joy of sexual intimacy was lost as men suffered from a self-consciousness that prevented them from losing themselves within the sensuous experience: 
'you do think about it [erection] ... and that probably takes away from the moment' [Participant quote, Hanly et al., 2014].

Men's attentions turned to 'avoiding a potentially embarrassing situation and finding new ways to retreat from the interaction before the possibility of a sexual encounter was raised' [Author quote, Bokhour et al., 2001, p.652], which further compounded the disconnection and absence of sexual intimacy:

'I'm afraid to start up with new women because of the inability to have full sexual contact with penetration. I am concerned about it and stay away from it'.

[Participant quote, Eliat-Tsanani et al., 2013, p.155]

Some men avoided any sort of physical closeness; in their pre-treatment intimate lives, kissing and cuddling was often a natural precursor to sexual intercourse, hence avoided post-treatment:

'I think you feel that touching and cuddling always led to something else, always led to sex before. And what if she wants to do that now? But I am not able to do that you know so you don't want to be forced into a situation that you can't. And you have to tell yourself and tell them that you can't'. [Participant quote, Letts, Tamlyn and Byer, 2010., p.497]

Men's withdrawal from sexual intimacy was governed by the psychological, as opposed to physical, damage left by treatment. They struggled to suspend their fears and engage in sexual intimacy in spite of recovered libido and physical health: 
'Sometimes inside of me I feel like I want to make love but it's not there so I just block it out of my mind'. [Participant quote, Rivers et al., 2011, p.109]

The nonlinear nature of men's experience of sexual intimacy is highlighted, as elements of avoidant coping could sometimes supersede, as opposed to follow, the use of proerectile assistive aids. Some men were conflicted about the idea of using such aids; whilst they were curious and wanted to explore potential benefits, their fears acted as a barrier. Rivers et al. (2001) reported as many as half of the men were reluctant to use any type of ED treatment of management.

\section{Breaking barriers: Constructing alternative intimacy}

Some men were able to resist the socially conditioned view of male sexuality as the ability to spontaneously engage in penetrative intercourse, and find different ways of enacting sexual intimacy and apply 'flexible' coping to develop 'alternative' ways of enacting sexual intimacy within their relationship [Beck et al., 2013; Bokhour et al., 2001; Gannon et al., 2010; Oliffe, 2005; Wittmann et al., 2014]. Consequently, men and their partners learnt to appreciate each other's bodies in ways that did not rely on penetrative intercourse, from oral sex to touch and sexual massage:

'We do more stroking; more exploring of the body, other parts of the body'.

[Participant quote, Wittmann et al., 2014, p.2511]

However, reconstructing sexual intimacy was an arduous process, as one participant explained 'the moral of this story is that we kept being committed to the relationship and 
to having a meaningful sex life' [Participant quote, Beck et al., 2013, p.1642].

Psychological and relational factors that contributed to the eventual construction of alternative forms of sexual intimacy were identified. One key study identified that 'participants needed to acknowledge and accept their own feelings' to develop alternative forms of sexual intimacy [Author quote, Beck et al., 2013, p.1642]. The 'ability to communicate about sexual losses' [Author quote, Wittmann et al., 2014, p.2513], perseverance and flexibility were also central to developing sexual intimacy without intercourse [Beck et al., 2013]. Couples who were able to develop alternative forms of sexual intimacy 'had a flexible attitude about the definition of sexual activity and were willing to experiment and take sexual risks with their partner' [Author quote, Beck et al., 2013, p.1641].

'Be patient. This thing, it's gonna take time. Even though I'm the most impatient person, I just said, well, there's only one thing and that is, if it takes two years or three years or five years and then you succeed, it's still worth it.' [Participant quote, Beck et al., 2013, p.1643]

Not all men were able to explore this form of intimacy and perceived that alternative sexual intimacy that did not rely on penile intercourse was a disconcerting prospect, especially if these activities had not been part of their pre-treatment lives [Hanly et al., 2014].

'I'm not comfortable with things like that [outer-course, manual stimulation or oral sex] ... they are not an option for her and I'. [Participant quote, Hanly et al., 2014, p6] 
However, for those men who were able to explore alternative forms of sexual intimacy, it was apparent that breaking free from phallocentric expressions of sexuality could generate an enhanced sense of relational openness and intimacy [Bokhour et al., 2001; Gannon et al., 2010; Hanly et al., 2014; Wittmann et al., 2014]. Developing alternatives helped shift the focus from erections and capacity for penetrative intercourse to mutual pleasure and closeness. In this way, sexual intimacy was not just restored, but reinvented and some men felt that they had become better lovers than before. As a result of their increased sexual experimentation, men reported their partners to be less conservative resulting in mutually satisfying intimate experiences:

'Our love life is getting better at being inventive'. [Participant quote, Oliffe, 2005, p.2256]

'It's more of a deeper...it's more than just an orgasm, it's...our relationship is better'. [Participant quote, Wittmann et al., 2014, p.2512]

Within the context of exploration and experimentation, some men also felt that they had become more attuned and responsive to their partner leading to a new appreciation and awareness of her body, feelings, needs and desires:

'It is not just the sexual stuff, it's about your feelings for each other. As a man, it's not just about satisfying yourself but it's about making sure that you're satisfying each other....that's with the sexual aspect, the emotional aspect, the communication. I find myself cuddling my wife a lot more often. I find myself being 
very considerate and watching her and anticipating...I'm more in tune with maybe how she's feeling or how she's responding now'. [Participant quote, Hanly et al., 2014]

The ability to find new ways of sustaining sexual intimacy buffered men against the sense of masculine failure associated with loss of sexual functioning [Beck et al., 2013]. In this way, their masculine gender identity and sexual self-concept were reaffirmed [Gannon et al., 2010; Hanly et al., 2014]. Men could create a new and valued role within their intimate relationships:

'I don't feel any less of a man [because of ED] because obviously it depends on your partner. There are other ways of pleasing a woman apart from actually entering her. You can use your tongue or use your hands...or that sort of thing. So if you are satisfying her then your feedback would be that you are still capable of giving her pleasure and I always felt that if you can give somebody pleasure in the relationship then you know that is where your masculinity comes not from the fact that...boom bang boom bang thank you ma'am sort of thing'. [Participant quote, Gannon et al., 2010, p.261]

For some of the men, this alternative form of sexual intimacy enabled them to develop realistic expectations of their current and future intimate relations and attain a level of acceptance and adjustment to the effects of treatment.

\section{DISCUSSION}


This is the first synthesis of the growing body of qualitative studies about sexual intimacy in the context of LPC. In addition to advancing theoretical understandings of sexual intimacy in the context of PC treatment, the findings provide insight into how clinicians can support their patients to construct an alternative sexual intimacy. This is important considering health care providers in oncology have multiple opportunities to interface with patients and those wishing to maintain sexual intimacy. This is also stipulated in the National Institute for Health and Care Excellence Guidelines on Prostate Cancer: Diagnosis and Treatment (NICE, 2008, further updated in 2014) which state that men with PC should be given 'the opportunity to talk to a healthcare professional experienced in dealing with psychosexual issues at any stage of the illness and its treatment' (NICE, 2014, p.14).

From a theoretical standpoint, men's experiences show the malleability of sexual intimacy in response to life experience and developmental influence. This is reminiscent of Giddens' concept of 'plastic sexuality', that is, sexuality once it is 'freed from the need of reproduction' (Giddens, 1993, p.2) and which transcends traditional age, gender, culture and partnership boundaries (Hordern and Street, 2007a). The importance of plastic sexuality has also been highlighted in other health care settings such as breast cancer, wherein women's ability to eschew cultural notions of sex for reproduction in favour of sex for pleasure and couple closeness was a key predictor of maintaining sexual intimacy after treatment (Vieira et al., 2013). We found sexual intimacy in the wake of LPC treatment was a fluid, dynamic phenomenon that could take different forms and change over time. This suggests that researchers and clinicians may wish to reconsider sexual intimacy in PC survivors afresh, through the lens of plastic sexuality, if we are to better understand and support the psychosexual process that underlies the cancer journey. 
The conceptual explanatory model proposed introduces a typology of four sexual intimacies that were recurrent in the context of LPG treatment generating a complex matrix with individual differences in inter-relationships and intersection. A pervasive theme identified across studies was 'destroyed intimacy'; an all-encompassing sense of loss and grief, which was particularly acute in initial aftermath of treatment. Some men were able to 'recover' and reported that, as a result of explorations of 'alternative intimacy', they were better lovers than before diagnosis. In this way, the reconstruction of sexual intimacy following PC treatment can be theoretically aligned with the psychological concept of post-traumatic growth (PTG); the view that individuals can achieve positive change through their struggle with trauma and sometimes a level of functioning that can even surpass what existed before the event occurred (Linley and Joseph, 2004; O’Leary and Ickovics, 1995). PTG is based on one general paradox: 'that out of loss there is gain' (Tedeschi and Calhoun, 2004, p.6). Therefore, helping men to emotionally and cognitively process their loss experience may represent an important way that clinicians can support men to rebuild sexual intimacy. This process may entail therapeutic 'grief work' (Stroebe and Stroebe, 1991), which can enable individuals to extract meaning and benefit from their experience (Nolen-Hoeksema and Davis, 2002) and develop emotion-focused coping, which may enable men to process and accept their loss and look towards feasible replacement of their lost sexual lives (Calhoun and Tadeschi, 2009). Although grief work is typically used as a therapeutic intervention for individuals who have lost a loved one, it has also been used successfully for individuals surviving illness, to help them cope with the physical, emotional and relational toll of their disease and its treatment. For example, as part of a cognitive-existential group therapy for women with breast cancer, grief work was used to help women accept and 
process the multiple losses brought about by their treatment (Kissane et al., 2004). In comparison to a control condition, women in the intervention group reported an enhanced ability to cope and achieve self-growth.

Ironically we found that the medical treatment typically offered to men to recoup their loss could impede the reconstruction of sexual intimacy as it created a reductionist, mechanistic portrayal of male sexuality. In offering chemical or mechanical treatment as the principal option for sexual difficulties, ED is framed as a purely physiological problem. This was incongruent with patients' views that sexual intercourse is broader and more complex. Hence, acknowledging that mechanical/chemical erections will not appeal to all men is important. Health care providers have the potential to debunk the myth that sexual intimacy requires penile erections. In order to ensure that sex talk is framed within patients' unique sexual beliefs system, we suggest that clinicians may wish to draw upon bio-psychosocial frameworks such as the Physical Pleasure-Relational Intimacy Model of Sexual Motivation (PRISM) as a springboard for discussion about sexual motivation and values (Beck, Robinson and Carlson, 2013). This model enables clinicians to elucidate the main motives for engaging in sexual activity (physical pleasure and/or relational intimacy) as a determining factor in the successful maintenance of satisfying sexual intimacy after PC treatment (Beck, Robinson and Carlson, 2013).

Men's disappointing experience of artificial sexual intimacy often led to avoidant coping; the attempt to reduce negative emotions associated with stressors perceived to be beyond ones control (Lazarus and Folkman, 1984). Men can appear indifferent to the impact of treatment upon their personal lives, making it difficult for clinicians to assess psychosexual distress (Gannon et al., 2010). Clinicians could benefit from training to 
assess emotional distress to routinely discuss and assess issues of sex and sexuality to prevent problems going undetected (Mick, Hughes and Cohen, 2003).

Finally, it was found that those participants who reconstructed sexual intimacy did so by diversifying their practices beyond hegemonic phallocentric models of sex. Therefore, a facilitative bio-psychosocial approach to sexuality is required, in which clinicians support men and their partners to forge intimacy that does not rely on erectile function. Alongside standard penile rehabilitation intervention, those men struggling with the psychosexual challenges of PC treatment may benefit from therapies such as couples counselling or cognitive behavioural therapy (CBT) to provide a broader exploratory framework. Indeed, a group-based CBT intervention for men who have undergone post-radical prostatectomy for LPC improved quality of life and sexual functioning, in particular sexual intimacy (Siddons, Wootten and Costello, 2013).

In light of the struggles that punctuate the cancer experience, it has long been acknowledged that health care providers require finely tuned communication skills to discuss such sensitive topics (Sheldon, 2005). Research across cancer types has suggested that the way health care professionals discuss sex has the potential to enhance couples capacity to maintain sexual intimacy in the wake of illness and help patients adjust to the iatrogenic effects of treatment (Hordern and Street, 2007b). Further research is needed to explore the communication needs in relation to psychosexual consequences of treatment. In particular, the psychosexual needs of gay men and/or single men are deserving of further attention, as research usually focuses on the psychosexual impact of PC treatment within long-term heterosexual relationships (Tucker, 2015). The dominance of heterosexual identities in social and cultural spaces raises additional challenges for 
non-heterosexual people in communicating about sexual matters (das Nair and Butler, 2012), including following PC treatment (Tucker, 2015). Whilst the LMAC model is not a stage model, there is some indication from the first- and second-order constructs that, for some individuals, the four recurring forms of intimacy may be particularly important at certain points in the PC trajectory. For example, the feelings of loss and grief associated with 'destroyed intimacy' were particularly prevalent when men were confronted with effects of treatment. Men often constructed 'alternative sexual intimacy' when they had exhausted other forms of restoring sexual intimacy (i.e. artificial intimacy). Further research may determine the existence of a common temporal order in the reconstruction of sexual intimacy following LPC treatment.

Meta-synthesis remains a relatively new approach and the challenges inherent to the method must be acknowledged. Some argue that the notion of scientific generalisability, which is implicit to meta-synthesis, compromises integrity and that the unique context of individual studies is lost in analytic amalgamation (Sandelowski et al., 1997; Zimmer, 2006). However, each reviewed study in the synthesis presents primary data, which maintains fidelity to the original study findings and promotes trustworthiness (Sim and Madden, 2008). Furthermore, the study involved 12 papers all of sufficient quality to include in the synthesis. This represents the optimal sample size - enough to engender a substantive level of formal theory, but not so large as to impede the depth of analysis and integration of themes (Bondas and Hall, 2007; Paterson, Thorne, Canam and Jillings, 2001). It must also be acknowledged that, like qualitative research more generally, the meta-synthesis process is inherently interpretive; different researchers may have generated a different conceptual framework (Malpass et al., 2009). This interpretative quality is valuable as it enables researchers to conceptualise and make sense of the data 
across studies, afresh, by drawing on theory not necessarily consulted by the original papers at that time. In this way, new knowledge and understanding can be achieved. The authors strived to maintain reflexivity throughout this process via debate and discussion, as recommended by Walsh and Downe (2006) to increase the trustworthiness of the final interpretation and findings.

In summary, this meta-synthesis revealed that maintaining sexual intimacy is a challenge for most men but not impossible. The emergence of a conceptual model explaining how and why some men are able to reconstruct sexual intimacy is important in advancing theoretical understandings and enabling clinicians and services to target and tailor sexual health management according to psychosexual need. On the basis of the synthesised findings, effective clinical communication and information about the psychosexual impact of treatment may help to better support men and their partners to recover satisfying sexual intimacy; more work is needed to further understand men's clinical communication needs in this area. 


\section{REFERENCES}

Andersen, B.L., Woods, X.A., \& Copeland, L.J. 1997. Sexual self-schema and sexual morbidity among gynecologic cancer survivors. Journal of Consulting and Clinical Psychology, 65(2), 221.

Badr, H., Carmack Taylor, C.L. 2009. Sexual dysfunction and spousal communication in couples coping with prostate cancer. Psycho-Oncology, 18(7), 735-746. doi:10.1002/pon.1449

Bayliss, K., Goodall, M., Chisholm, A., Fordham, B., Chew-Graham, C., Riste, L. et al. 2014. Overcoming the barriers to the diagnosis and management of chronic fatigue syndrome/ME in primary care: a meta synthesis of qualitative studies. BMC Family Practice, 15(1), 44. doi:10.1186/1471-2296-15-44.

Beck, A.M, Robinson, J.W., \& Carlson, L.E. 2009. Sexual intimacy in heterosexual couples after prostate cancer treatment: What we know and what we still need to learn. Urologic Oncology, 27(2),137-43. doi:10.1016/j.urolonc.2007.11.032

Beck, A.M., Robinson, J.W., \& Carlson, L.E. 2013. Sexual values as the key to maintaining satisfying sex after prostate cancer treatment: the physical pleasurerelational intimacy model of sexual motivation. Archives of Sexual Behaviour, 42(8), 1637-47. doi:10.1007/s10508-013-0168-z.

Bokhour, B.G., Clark, J.A., Inui, T. S., Silliman, R.A., \& Talcott, J.A. 2001. Sexuality after treatment for early prostate cancer: Exploring the meanings of "erectile dysfunction.” Journal of General Internal Medicine, 16(10),649-655. doi:10.1111/j.1525-1497.2001.00832.x 
Bondas, T., Hall, E.O. 2007. Challenges in approaching metasynthesis research.

Qualitative Health Research, 17(1),113-21. doi:10.1177/1049732306295879

Britten, N., Campbell, R., Pope, C., Donovan, J., Morgan, M., \& Pill, R. 2002. Using meta-ethnography to synthesise qualitative research: a worked example. Journal of Health Service Research Policy, 7(4),209-215. doi:10.1258/135581902320432732

Calhoun, L.G., Tedeschi, R. G. 1998. Posttraumatic growth: Future directions. In R.G. Tedeschi, C.L. Park \& L.G. Calhoun (Eds.), Posttraumatic growth: Positive changes in the aftermath of crisis (pp. 215-238). USA: Routledge

Cancer Research UK 2012. Statistics and outlook for prostate cancer. Retrieved 1 November 2013, from http://cancerhelp.cancerresearchuk.org/type/prostatecancer/treatment/statistics-and-outlook-for-prostate-cancer

Chung, E., Brock, G. 2013. Sexual rehabilitation and cancer survivorship: A state of art review of current literature and management strategies in male sexual dysfunction among prostate cancer survivors. The Journal of Sexual Medicine, 10(S1), 102111. doi:10.1111/j.1743-6109.2012.03005.x.

Critical Appraisal Skills Programme (CASP) 2010. 10 Questions to Help You Make Sense of Qualitative Research. Oxford, UK: CASP.

das Nair, R., Butler, C. 2012. Intersectionality, sexuality and psychological therapies: Working with lesbian, gay and bisexual diversity. UK: John Wiley \& Sons. de Moraes Lopes, M.H., Higa, R., Cordeiro, S.N., Rodrigues Estapê, N.A., Levi D'ancona C.A., Turato, E.R. 2012. Life experiences of Brazilian men with urinary incontinence and erectile dysfunction following radical prostatectomy. Journal of 
Wound, Ostomy and Continence Nursing, 39(1), 90-4. doi:10.1097/WON.0b013e3182383eeb

Dixon-Woods, M., Sutton, A., Shaw, R., Miller, T., Smith, J., Young, B., Bonas S., Booth A., Jones D.R. 2007. Appraising qualitative research for inclusion in systematic reviews: a quantitative and qualitative comparison of three methods. Journal of health services research \& policy, 12(1), 42-47. doi:10.1258/135581907779497486

Eilat-Tsanani, S., Tabenkin, H., Shental, J., Elmalah, I., Steinmetz, D. 2013. Patients' perceptions of radical prostatectomy for localized prostate cancer: a qualitative study. Israel Medical Association Journal, 15(3), 153-7.

Epstein, M.M., Edgren, G., Rider, J.R., Mucci, L.A., \& Adami, H.O. 2012. Temporal trends in cause of death among Swedish and US men with prostate cancer. Journal of the National Cancer Institute, 104(17), 1335-1342. doi:10.1093/jnci/djs299

Ferlay, J., Soerjomataram, I., Dikshit, R., Eser, S., Mathers, C., Rebelo, M. et al. 2015. Cancer incidence and mortality worldwide: sources, methods and major patterns in GLOBOCAN 2012. International Journal of Cancer, 136(5), E359-E386. doi:10.1002/ijc.29210

Gannon, K., Guerro-Blanco, M., Patel, A., Abel, P. 2010. Re-constructing masculinity following radical prostatectomy for prostate cancer. Aging Male, 13(4):258-64. doi:10.3109/13685538.2010.487554.

Giddens, A. 1993. The nature of modernity: Modernity and self-identity, love and sexuality. London, UK: The Macmillan Press Ltd. 
Hawkins, Y., Ussher, J., Gilbert, E., Perz, J., Sandoval, M., Sundquist, K. 2009. Changes in sexuality and intimacy after the diagnosis and treatment of cancer: the experience of partners in a sexual relationship with a person with cancer. Cancer Nursing, 32(4):271-80. doi:10.1097/NCC.0b013e31819b5a93.

Heidenreich, A., Bastian, P.J., Bellmunt, J., Bolla, M., Joniau, S., van der Kwast, T. et al. 2014. EAU guidelines on prostate cancer. part 1: screening, diagnosis, and local treatment with curative intent-update 2013. European Urology, 65(1):124-37. doi:10.1016/j.eururo.2013.09.046.

Hanly, N., Mireskandari, S., \& Juraskova, I. 2014. The struggle towards 'the New Normal': a qualitative insight into psychosexual adjustment to prostate cancer. BMC Urology,_14, (56). doi:10.1186/1471-2490-14-56.

Hedestig, O., Sandman, P.O., Tomic, R., \& Widmark, A. 2005. Living after radical prostatectomy for localized prostate cancer: a qualitative analysis of patient narratives. Acta Oncologica, 44(7), 679-86. doi:10.1080/02841860500326000

Hordern, A.J., \& Street, A.F. 2007a. Constructions of sexuality and intimacy after cancer: patient and health professional perspectives. Social Science \& Medicine , 64(8), 1704-18. doi:10.1016/j.socscimed.2006.12.012

Hordern, A. J., \& Street, A. F. 2007b. Communicating about patient sexuality and intimacy after cancer: mismatched expectations and unmet needs. Medical Journal of Australia, 186(5), 224.

Hordern, A. 2008. Intimacy and sexuality after cancer: a critical review of the literature. Cancer Nursing, 31(2), E9-E17. doi:10.1097/01.NCC.0000305695.12873.d5

Jackson, L.J., \& Roberts, T.E. 2015. Conceptualising quality of life outcomes for women participating in testing for sexually transmitted infections: a systematic review 
and meta-synthesis of qualitative research. Social Science \& Medicine, 143, 162170.

Jensen, L.A., \& Allen, M.N. 1996. Meta-synthesis of qualitative findings. Qualitative Health Research, 6(4), 553-560. 10.1177/104973239600600407

Katz, A. 2005. The sounds of silence: sexuality information for cancer patients. Journal of Clinical Oncology, 23(1):238-41.doi:10.1200/JCO.2005.05.101

Kissane, D. W., Love, A., Hatton, A., Bloch, S., Smith, G., Clarke, D. M. et al. 2004. Effect of cognitive-existential group therapy on survival in early-stage breast cancer. Journal of Clinical Oncology, 22(21), 4255-4260.

Lazarus, R. S., \& Folkman, S. 1984. Stress, Appraisal, and Coping. New York: Springer.

Letts, C., Tamlyn, K., \& Byers, E.S. 2010. Exploring the impact of prostate cancer on men's sexual well-being. Journal of Psychosocial Oncology, 28(5), 490-510. doi:10.1080/07347332.2010.498457.

Linley, P.A., \& Joseph, S. 2004. Positive Change Following Trauma and Adversity: A Review. Journal of Traumatic Stress, 17(1), 11-21. doi:10.1023/B:JOTS.0000014671.27856.7e

Malpass, A., Shaw, A., Sharp, D., Walter, F., Feder, G., Ridd, M. et al. 2009. "Medication career" or "moral career"? The two sides of managing antidepressants: a meta-ethnography of patients' experience of antidepressants. Social Science \& Medicine, 68(1), 154-68. doi:10.1016/j.socscimed.2008.09.068.

Mick, J., Hughes, M. \& Cohen, M. 2003. Sexuality and cancer: How oncology nurses can address it BETTER. Oncology Nursing Forum, 30(S2), 152-153.

Moher, D., Liberati, A., Tetzlaff, J., Altman, D.G., The PRISMA Group. 2009. Preferred Reporting Items for Systematic Reviews and Meta-Analyses: The PRISMA Statement. PLoS Med, 6(6): e1000097. doi:10.1371/journal.pmed1000097 
National Institute for Health and Care Excellence 2014. Prostate cancer: Diagnosis and treatment. Full guideline. CG175.

Navon, L., Morag, A. 2003. Advanced prostate cancer patients' ways of coping with the hormonal therapy's effect on body, sexuality, and spousal ties. Qualitative Health Research, 13(10). doi:1378-92.10.1177/1049732303258016

Noblit, G.W., Hare, R.D. 1988. Meta-ethnography: Synthesising qualitative studies. London, UK: Sage.

Nolen-Hoeksema, S., Davis, C.G. 2002. Positive responses to loss: perceiving benefits and growth. In S.J. Lopez C.R. \& Snyder (Eds.), Handbook of Positive Psychology. (pp. 598-606). New York, US: Oxford University Press.

O'Leary, V., Ickovics, J. 1995. Resilience and thriving in response to challenge: An opportunity for a paradigm shift in women's health. Women's Health, 1(2), 121142.

Oliffe, J. 2005. Constructions of masculinity following prostatectomy-induced impotence. Social Science \& Medicine, 60(10), 2249-59. doi:10.1016/j.socscimed.2004.10.016

Paterson, B.L., Thorne, S.E., Canam, C., Jillings, C. 2001.Meta-study of qualitative health research. A practical guide to meta-analysis and meta-synthesis. Thousand Oaks, CA: Sage.

Perz, J., Ussher, J.M., Gilbert, E. 2013. Constructions of sex and intimacy after cancer: Q methodology study of people with cancer, their partners, and health professionals. BMC Cancer. 13(1), 270. doi:10.1186/1471-2407-13-270. 
Petticrew, M., Roberts, H. 2006. Systematic Reviews in the Social Sciences A Practical Guide. Oxford, UK: Blackwell Publishing.

Prostate Cancer UK 2013. Prostate cancer facts and figures. Retrieved 1 November 2013, from http://prostatecanceruk.org/information/prostate-cancer-facts-and-figures

Quinn, M. Babb, P. 2002. Patterns and trends in prostate cancer incidence, survival, prevalence and mortality. Part I: international comparison. BJU International, 90(2), 162-73. doi:10.1046/j.1464-410X.2002.2822.x

Ries, L. A.G., Melbert, D., Krapcho, M., Stinchcomb, D.G., Howlader, N., Horner, M., et al. 2008. SEER cancer statistics review, 1975-2005. Bethesda, MD: National Cancer Institute, 1975-2005.

Rivers, B.M., August, E.M., Gwede, C.K., Hart, A. Jr, Donovan, K.A., Pow-Sang, J.M. et al. 2011. Psychosocial issues related to sexual functioning among AfricanAmerican prostate cancer survivors and their spouses. Psychooncology, 20(1), 106-10. doi:10.1002/pon.1711.

Sacks, H.S., Reitman, D., Pagano, D., Kupelnick, B. 1996. Meta-analysis: An update. Mount Sinai Journal of Medicine, 63(3-4), 216-224.

Sandelowski, M., Docherty, S., Emden, C. 1997. Focus on qualitative methods. Qualitative metasynthesis: issues and techniques. Research in Nursing \& Health, 20(4), 365-71. doi:10.1002/(SICI)1098-240X(199708)

Sanders, S., Pedro, L.W., Bantum, E.O., Galbraith, M.E. 2006. Couples surviving prostate cancer: Long-term intimacy needs and concerns following treatment. Clinical Journal of Oncology Nursing, 10(4),503-8. doi:10.1188/06.CJON.503508 
Schultz, W.C.M., van de Wiel, H.B.M. 2003. Sexuality, intimacy and gynaecological cancer. Journal of Sex and Marital Therapy, 29(1), 121-8. doi:10.1080/713847128

Shaw, R., Booth, A., Sutton, A., Miller, T., Smith, J., Young, B. et al. 2004. Finding qualitative research: an evaluation of search strategies. BMC Medical Research Methodology, 4, 5-10. doi:10.1186/1471-2288-4-5

Sheldon, L.K. 2005. Communication in oncology care: the effectiveness of skills training workshops for healthcare providers. Clinical Journal of Oncology Nursing, 9(3), 305-12. doi:10.1188/05.CJON.305-312

Siddons, H.M., Wootten, A.C., \& Costello, A.J. 2013. A randomised, wait-list controlled trial: evaluation of a cognitive-behavioural group intervention on psycho-sexual adjustment for men with localised prostate cancer. Psycho-Oncology, 22(10), 2186-2192. doi:10.1002/pon

Siegel, R., Naishadham, D., Jemal, A. 2013. Cancer statistics, 2013. CA: A Cancer Journal for Clinicians, 63(1), 11-30. doi:10.3322/caac.21166

Sim, J., Madden, S. 2008. Illness experience in fibromyalgia syndrome: a metasynthesis of qualitative studies. Social Science \& Medicine, 67(1), 57-67. doi:10.1016/j.socscimed.2008.03.003.

Steinke, E.E. 2005. Intimacy needs and chronic illness: strategies for sexual counseling and self-management. Journal of Gerontological Nursing, 31(5), 40-50. doi:10.3928/0098-9134-20050501-08 
Strike, K., Posner, G. 1983. Types of synthesis and their criteria. In S. Ward \& L. Reed Knowledge Structure and Use. Philadelphia: Temple University Press.

Stroebe, M., \& Stroebe, W. 1991. Does "grief work" work? Journal of Consulting and Clinical Psychology, 59(3), 479.

Tedeschi, R.G., Calhoun, L.G. 2004. " Posttraumatic growth: Conceptual foundations and empirical evidence". Psychological Inquiry, 15(1),1-18. doi:10.1207/s15327965pli1501_01

Tracey, E.A., Baker, D., Chen, W., Stavrou, E., Bishop, J. 2007. Cancer in New South Wales: Incidence and Mortality 2005. Sydney: Cancer Institute NSW.Tucker, S.R. 2015. Uniting the body and mind in prostate cancer: A qualitative exploration of the psychosexual impact of prostate cancer treatment and related clinical communication needs. Unpublished doctoral dissertation, University of Manchester, UK.

Vieira, E.M., Ford, N.J., Santos, M.A., Junqueira, L.C., Giami, A. 2013. Representations of nurses regarding sexuality of women treated for breast cancer in Brazil. Cadernos de Saude Publica, 29(10),2049-56. doi:10.1590/0102-311X00158512

Zimmer, L. 2006. Qualitative meta-synthesis: a question of dialoguing with texts. Journal of Advanced Nursing, 53(3),311-8. doi:10.1111/j.1365-2648.2006.03721.x

Walsh, D., Downe, S. 2006. Appraising the quality of qualitative research. Midwifery, 22, 108-119. doi:0.1016/j.midw.2005.05.004

Wilmoth, M.C. 2001. The aftermath of breast cancer: an altered sexual self. Cancer Nursing. 24(4),278-86. doi:10.1097/00002820-200108000-00006

Wittmann, D., Carolan, M., Given, B., Skolarus, T.A., An, L., Palapattu, G. et al. 2014. Exploring the role of the partner in couples' sexual recovery after surgery for 
prostate cancer. Support Care Cancer, 22(9):2509-15. doi:10.1007/s00520-0142244-x. 
Appendix 1. Example of a search strategy (Embase)

\begin{tabular}{|c|c|}
\hline \# & Term (result) \\
\hline 1 & Prostate cancer $(149,505)$ \\
\hline 2 & Treatment or side effect\$ or treatment effect\$ $(4,984,527)$ \\
\hline 3 & 1 and $2(63,440)$ \\
\hline 4 & $\begin{array}{l}\text { Qualitative or experience or impact or interview\$ or focus } \\
\text { group } \$(1,818,303)\end{array}$ \\
\hline 5 & Sexual intimacy or sexuality or sex\$ or intimacy $(990,769)$ \\
\hline 6 & $1,2,4$ and $5(1001)$ \\
\hline
\end{tabular}

Note: A broad approach to the search strategy was used. Hand searching supplemented the search strategy. 
Table 1: Overview of included studies

\begin{tabular}{|c|c|c|c|c|}
\hline $\begin{array}{l}\text { Source paper } \\
\& \text { Country Setting }\end{array}$ & $\begin{array}{l}\text { Participants (age in years; marital } \\
\text { status; ethnicity) }\end{array}$ & $\begin{array}{l}\text { Time between treatment } \\
\text { and interview }\end{array}$ & Methods, recruitment and analysis & $\begin{array}{l}\text { Appraisal of } \\
\text { quality } \\
\text { and relevance }\end{array}$ \\
\hline $\begin{array}{l}\text { Beck, Robinson \& Carlson } \\
\text { (2013); } \\
\text { Canada }\end{array}$ & $\begin{array}{l}17 \text { men aged } 53-84 \text { years }(\text { mean }=64) \\
15 \text { married, } 2 \text { in intimate relationships; } \\
\text { Ethnicity not stated }\end{array}$ & $\begin{array}{l}3 \text { months }-7 \text { years }(\text { mean }= \\
2.8)\end{array}$ & $\begin{array}{l}\text { Semi-structured interviews; } \\
\text { Theoretical sample identified through advertisements, presentations, word-of-mouth at local } \\
\text { cancer centres and support groups; } \\
\text { Grounded theory }\end{array}$ & Key;2,2,2 \\
\hline $\begin{array}{l}\text { Bokhour, Clark, Inui, } \\
\text { Silliman \& Talcott, } \\
\text { (2001); } \\
\text { America }\end{array}$ & $\begin{array}{l}48 \text { men aged } 50-79 \text { years; } \\
\text { Marital status not stated; } \\
\text { White or African-American }\end{array}$ & 12-24 months & $\begin{array}{l}\text { Focus groups; } \\
\text { Recruited from lists of patients at two cancer care sites; } \\
\text { Grounded theory }\end{array}$ & Key;2,2,2 \\
\hline $\begin{array}{l}\text { de Moraes Lopes et } \\
\text { al.(2012); } \\
\text { Brazil }\end{array}$ & $\begin{array}{l}10 \text { men aged } 48-74 \text { years; } \\
7 \text { married, } 2 \text { in intimate relationships, } 1 \\
\text { divorced; } \\
\text { Ethnicity not stated }\end{array}$ & 1 year, 6 months -25 years & $\begin{array}{l}\text { Semi-structured interviews; } \\
\text { Intentional sampling method, participants identified from a urology clinic; } \\
\text { Content Analysis }\end{array}$ & Satisfactory; $2,1,1$ \\
\hline $\begin{array}{l}\text { Eilat-Tsanani, Tabenkin, } \\
\text { Shental, Elmalah, \& } \\
\text { Steinmetz, (2013); } \\
\text { Israel }\end{array}$ & $\begin{array}{l}22 \text { men aged } 60-81 \text { years }(\text { mean }=73 \text { ); } \\
16 \text { married, } 5 \text { divorced, } 1 \text { in intimate } \\
\text { relationship; } \\
\text { Mixed ethnicity }\end{array}$ & $>1$ year & $\begin{array}{l}\text { Semi-structured interviews; } \\
\text { Recruited via a urology department; } \\
\text { Unspecified qualitative analysis }\end{array}$ & Satisfactory; $2,1,1$ \\
\hline $\begin{array}{l}\text { Gannon, Guerro-Blanco, } \\
\text { Patel \& Abel, (2010); } \\
\text { UK, (London) }\end{array}$ & $\begin{array}{l}7 \text { men aged } 58-70 \text { years (mean }=63 \text { ); } \\
5 \text { married/partner (no further details } \\
\text { available); } \\
4 \text { British, } 1 \text { Irish, } 1 \text { African, } 1 \text { Asian }\end{array}$ & $7-15$ months & $\begin{array}{l}\text { Semi-structured interviews; } \\
\text { Recruited via a urology department; } \\
\text { Foucauldian Discourse Analysis }\end{array}$ & Satisfactory; $1,2,2$ \\
\hline $\begin{array}{l}\text { Hanly, Mireskandari \& } \\
\text { Juraskova, (2014); } \\
\text { Australia }\end{array}$ & $\begin{array}{l}21 \text { men aged } 50-69 \text { years; } \\
16 \text { married, } 2 \text { single, } 2 \text { divorced, } 1 \text { in } \\
\text { intimate relationship; } \\
\text { Ethnicity not stated }\end{array}$ & $\begin{array}{l}6 \text { men }<12 \text { months, } \\
13<3 \text { years, } \\
2(9 \%)<5 \text { years. }\end{array}$ & $\begin{array}{l}\text { Semi-structured interviews; } \\
\text { Recruited via PC support group newsletter; } \\
\text { Thematic analysis }\end{array}$ & Key; 2,2,2 \\
\hline
\end{tabular}




\begin{tabular}{|c|c|c|c|c|}
\hline $\begin{array}{l}\text { Hedestig, Sandman, } \\
\text { Tomic \& Widmark, } \\
\text { (2005); } \\
\text { Sweden }\end{array}$ & $\begin{array}{l}10 \text { men aged } 61-69 \text { years; } \\
9 \text { married, } 1 \text { widower; } \\
\text { Ethnicity not stated }\end{array}$ & 12-34 months & $\begin{array}{l}\text { Narrative interviews; } \\
\text { Recruited via database containing registration details of PC patients; } \\
\text { Content analysis }\end{array}$ & Satisfactory; $1,1,2$ \\
\hline $\begin{array}{l}\text { Letts, Tamlyn \& Byers, } \\
\text { (2010); } \\
\text { Canada }\end{array}$ & $\begin{array}{l}19 \text { men aged } 49-74 \text { years (mean }=65) \text {; } \\
17 \text { married, } 2 \text { in intimate relationships; } \\
\text { Caucasian }\end{array}$ & $1-5$ years $($ mean $=2.5)$ & $\begin{array}{l}\text { Semi-structured interviews; } \\
\text { Purposeful sample recruited through PC support groups; } \\
\text { Framework methodology }\end{array}$ & Key;2, 2, 2 \\
\hline $\begin{array}{l}\text { Oliffe (2005); } \\
\text { Australia }\end{array}$ & $\begin{array}{l}15 \text { men aged } 46-74 \text { years }(\text { mean }=57) \\
\text { All in intimate relationships; } \\
\text { Anglo-Australian }\end{array}$ & $3-72$ months $($ mean $=21)$ & $\begin{array}{l}\text { Semi-structured interviews; } \\
\text { Purposeful criterion sample identified from two PC support groups and advertisements; } \\
\text { Social constructionist gendered framework }\end{array}$ & Key;2,2,2 \\
\hline $\begin{array}{l}\text { Rivers et al. (2011); } \\
\text { America }\end{array}$ & $\begin{array}{l}12 \text { men aged } 51-70 \text { years }(\text { mean }=59) \text {; } \\
\text { All married; } \\
\text { Ethnicity not stated }\end{array}$ & $<5$ years & $\begin{array}{l}\text { Semi-structured interviews; } \\
\text { Purposive sample; } \\
\text { Constant comparison method and content analysis }\end{array}$ & Satisfactory $; 1,1,1$ \\
\hline $\begin{array}{l}\text { Sanders, Pedro, Bantum \& } \\
\text { Galbraith, (2006); } \\
\text { America }\end{array}$ & $\begin{array}{l}10 \text { men aged } 45-81 \text { years }(\text { mean }=63) \text {; } \\
\text { All in intimate relationships; } \\
\text { 'White' }\end{array}$ & $1.5-8$ years & $\begin{array}{l}\text { Focus group; } \\
\text { Patients identified through a previous study conducted by a co-author; } \\
\text { No analytic procedure defined }\end{array}$ & Satisfactory; $1,1,1$ \\
\hline $\begin{array}{l}\text { Wittmann et al. (2014); } \\
\text { America }\end{array}$ & $\begin{array}{l}10 \text { men (age mean }=62) \text {; } \\
\text { All in intimate relationships; } \\
\text { Ethnicity not stated }\end{array}$ & $\begin{array}{l}6-21 \text { months }(\text { mean }= \\
13.6)\end{array}$ & $\begin{array}{l}\text { Semi-structured interviews; } \\
\text { Participants from a previous study contacted by mail; } \\
\text { Grounded theory }\end{array}$ & Satisfactory $; 2,1,2$ \\
\hline
\end{tabular}


Figure 1: PRISMA flow chart detailing the process of study identification

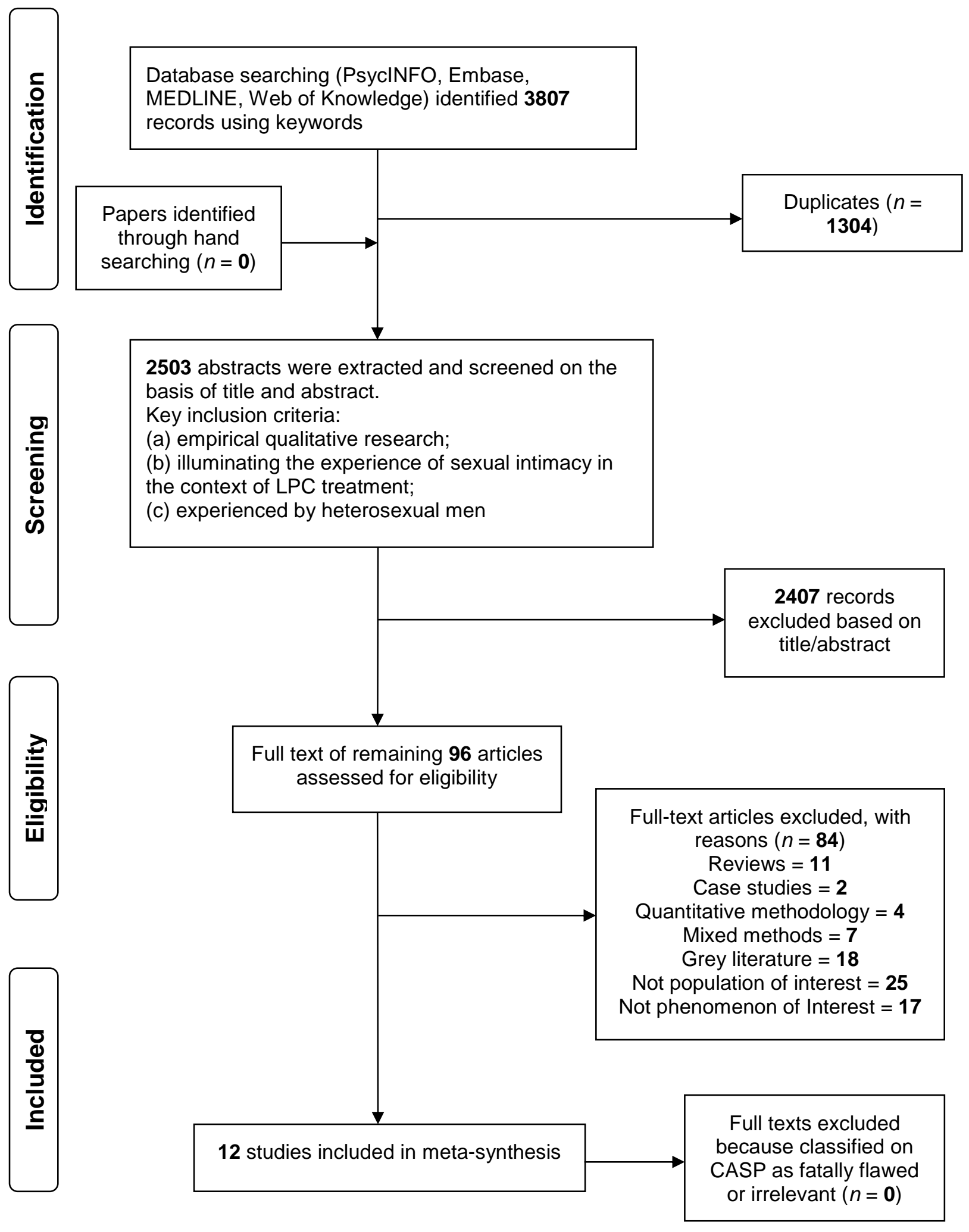

(Two-column fitting image) 
Figure 2. LMAC (Loss, Motions, Avoidance and Construction) Explanatory

Model: Forms of sexual intimacy in the context of localised prostate cancer treatment.

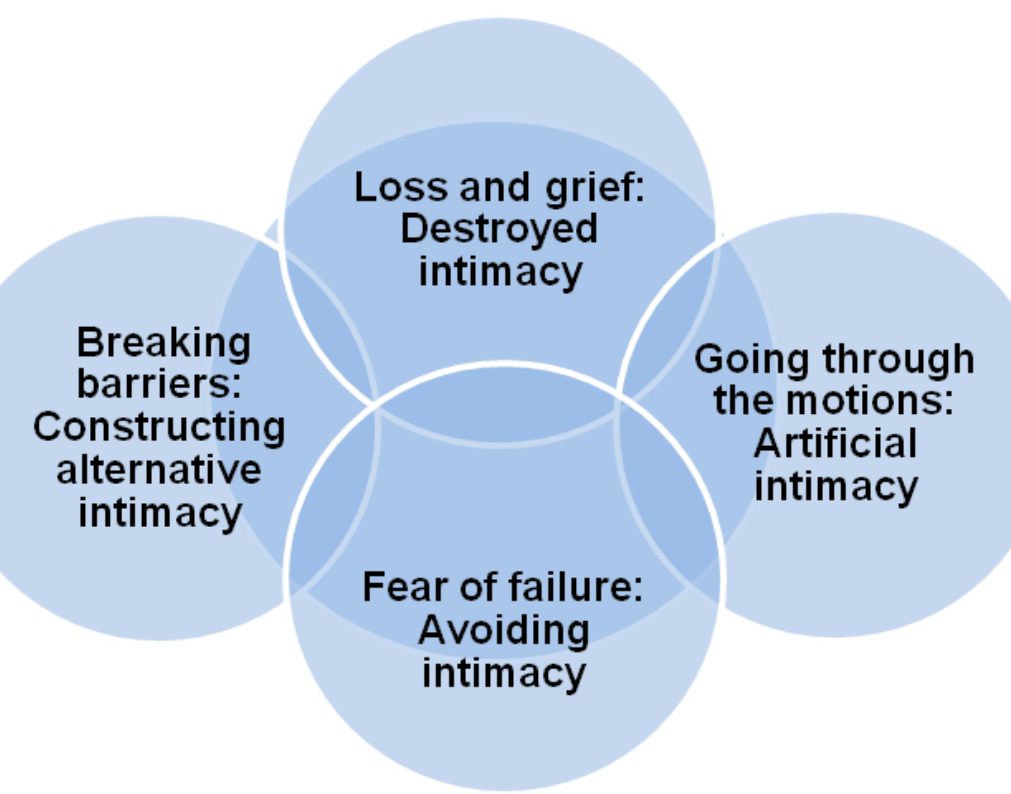

